Editorial

\title{
Volume 1: First Steps for SGAMR
}

\author{
${ }^{1}$ Chiara Bedon, ${ }^{2}$ Mario D'Aniello and ${ }^{3}$ Flavio Stochino \\ ${ }^{I}$ Department of Engineering and Architecture, University of Trieste, Trieste, Italy \\ ${ }^{2}$ Department of Structural Engineering, University of Naples Federico II, Naples, Italy \\ ${ }^{3}$ Department of Civil, Environmental and Architectural Engineering, University of Cagliari, Cagliari, Italy
}

Summer 2017 is approaching when the International Journal of Structural Glass and Advanced Materials Research starts to walk and the "Volume 1" contains its first outcomes (Bedon et al., 2017). It is worth of interest that the attention of the contributors is on glass... but not only,... and this represents a promising step for the journal growth and evolution. In this regard, a special thanks is for all the contributors and involved reviewers, as well as for the technical staff that works in background.

Stochino et al. (2017) present original laboratory experiments dedicated to the analysis and behaviour of reinforced recycled slabs. The recycled concrete was made with natural and coarse recycled aggregates and produced by crushed concrete with five concrete mixes (with up to $100 \%$ the replacement percentage of coarse natural aggregate). The paper shows that the use of coarse recycled aggregates reduces the mechanical performance, with progressive decrease of compressive strength (29\% maximum), tensile strength $(13 \%)$ and modulus of elasticity with the increase of replacement percentage of recycled aggregate. No evident reduction in the cracking load, or modification in the cracking pattern, is indeed observed, compared to normal concrete. In conclusion, the paper experimentally proves that the use of recycled concrete mixes for slabs (and structural elements in general) should be strongly encouraged, also at the standardization level.

Also (Santoro and Kripka, 2017) study the performance of reinforced concrete mixes, but with a focus on their environmental effect (i.e., carbon dioxide emissions) under different life cycle phases. The design of size and characteristic strength of materials should be properly analyzed. The production phases of concrete, with the choice of the most suitable concrete mixture for the defined strength and loads in operational conditions, but also the maintenance and the carbonation stages are equally important. The demolition of the structure itself should already focus (at the time of design studies) on the final destination of concrete, either for landfills or for recycling, in which questions of carbonation may contribute to minimize the final carbon emissions.

Going back to glass, Zhang and Bedon (2017) review the current status of knowledge (and especially the available research efforts in support of design) on the vulnerability of glass structures and components in buildings, under the effects of blast loads. As far as such a brittle constructional material is subjected to extreme design loads like explosions, a multitude of aspects should be taken into account to minimize the number of injuries and to optimize the expected structural behaviour.

The concept of "vulnerability" in engineering applications, as known, can take different forms and faces. Often, it is commonly referred to load-bearing materials and systems that are subjected to extreme design loads can take various forms and can involve different levels of analysis, so as to ensure appropriate safety levels and protection for the occupants/customers. This is the topic addressed by (Papán et al., 2017), with careful attention to the seismic vulnerability assessment of a case-study production factory in Slovak Republic. An original experimental record is presented, with a focus on the road traffic induced vibrations from a highway that is located in the surrounding of the factory place. Based on experimental acquisitions, a Finite Element numerical investigation is presented to assess the sensitivity of the factory region to various potential scenarios of induced vibrations.

Enjoy this volume!

The Editor in Chief and the Associate Editors.

\section{References}

Bedon, C., D'Aniello, M., Luible, A. \& Stochino, F. (2017). International Journal of Structural Glass and Advanced Materials Research: A New Open Platform for Materials Science. International Journal of Structural Glass and Advanced Materials Research, 1(1), 1-2.

Papán, D., Krkošková, K. \& Papánová, Z. (2017). Theoretical Analysis and Technical Seismicity Effect Assessment onto the Production Factory due to Traffic in Prešov City. International Journal of Structural Glass and Advanced Materials Research, 1(2), 24-31.

Santoro, J. F. \& Kripka, M. (2017). Studies on Environmental Impact Assessment of Reinforced Concrete in Different Life Cycle Phases. International Journal of Structural Glass and Advanced Materials Research, 1(2), 32-40. 
Chiara Bedon et al. / International Journal of Structural Glass and Advanced Materials Research 2020, Volume 4: 180.181 DOI: 10.3844/sgamrsp.2020.180.181

Stochino, F., Pani, L., Francesconi, L. \& Mistretta, F. (2017). Cracking of Reinforced Recycled Concrete Slabs. International Journal of Structural Glass and Advanced Materials Research, 1(1), 3-9.
Zhang, X. \& Bedon, C. (2017). Vulnerability and Protection of Glass Windows and Facades under Blast: Experiments, Methods and Current Trends. International Journal of Structural Glass and Advanced Materials Research, 1(2), 10-23. 